\section{NANOPARTICLE EMISSION DURING CUTTING OPERATION OF CARBON NANOTUBE REINFORCED POLYCARBONATE COMPOSITES AND RECYCLING EFFECT}

${ }^{1}$ Pongsit Boonruksa*, ${ }^{2}$ Dhimiter Bello, ${ }^{3}$ Jacqueline Isaacs, ${ }^{4}$ Joey Mead, ${ }^{2}$ Susan Woskie. ${ }^{1}$ School of Occupational Health and Safety, Suranaree University of Technology, Nakhon Ratchasima, Thailand; ' ${ }^{2}$ Department of Public Health, University of Massachusetts Lowell, MA, USA; ${ }^{3}$ Department of Mechanical and Industrial Engineering, Northeastern University, MA, USA; ${ }^{4}$ Department of Plastics Engineering, University of Massachusetts Lowell, MA, USA

\subsection{6/oemed-2018-ICOHabstracts.553}

Introduction Carbon nanotubes (CNTs) are widely used as a nanofiller in polymer composites to improve the quality of neat polymers. However, the use of CNT are threatened by concerns over its toxicology. The purpose of this study was to investigate the potential emissions of NPs and CNTs during cutting CNT polycarbonate composites (CNT/PC) and evaluate the impact of recycling CNT/PC (up to 20 cycles) on the emission during cutting operation.

Methods Cutting CNT/PC bars was conducted using a saw with a diamond coated blade at $1600 \mathrm{rpm}$ in an enclosing chamber. Particle number concentration and size distribution emitted from cutting were measured using real time instruments: a fast mobility particle sizer and an aerodynamic mobility particle sizer. Particles were also collected using an electrostatic precipitator and examined by a transmission electron microscope for particle morphology.

Result After saw's motor background correction, cutting of $\mathrm{CNT} / \mathrm{PC}$ released airborne nanoparticles with geometric mean of particle concentrations from $4.01 \times 10^{4}$ to $1.47 \times 10^{5}$ particles $/ \mathrm{cm}^{3}$, but we did not find the effect of recycling $\mathrm{CNT} / \mathrm{PC}$ on nanoparticle emission during cutting operation. The count median diameter of particles varied from 21 to $24 \mathrm{~nm}$. Free CNTs were not observed during cutting CNT/ PC; however, particles with extruding fibres or CNTs, and respirable fibres were found.

Discussion Our findings were consistent with several studies which investigated and characterised airborne particles generated from cutting CNT composites. Although free CNTs were not observed, we did find particles with CNTs embedded in the PC matrix, particles with CNTs or fibre extrusions, and respirable fibres produced during cutting $\mathrm{CNT} / \mathrm{PC}$. The health risk and hazard profile of these particles is limited and need for future research. In the meanwhile, exposure controls should be implemented during finishing CNT composites.

\section{FACTORS INFLUENCING THE INCREASE OF CONCENTRATION OF AIRBORNE ENDOTOXIN, MOUSE AND RAT ALLERGENS IN AN ANIMAL FACILITY}

\footnotetext{
${ }^{1} S$ Di Renzi, ${ }^{1} \mathrm{~A}$ Chiominto, ${ }^{1} \mathrm{AM}$ Marcelloni, ${ }^{1} \mathrm{P}$ Melis, ${ }^{2} \mathrm{~S}$ Massari, ${ }^{3} \mathrm{MC}$ Riviello, ${ }^{4} \mathrm{~A}$ Wirz, ${ }^{1} \mathrm{R}$ Sisto, 'E Paba, 'MC D'Ovidio*. 'Italian Workers' Compensation Authority (INAIL), Department of Occupational and Environmental Medicine, Epidemiology and Hygiene, Monte Porzio Catone (Rome), Italy; 'Italian Workers' Compensation Authority (INAIL), Department of Occupational and Environmental Medicine, Epidemiology and Hygiene, Rome, Italy; ${ }^{3}$ National Research Council (CNR), Institute of Cell Biology and Neurobiology, Rome, Italy; ${ }^{4}$ RCCS Santa Lucia Foundation, Rome, Italy
}

\subsection{6/oemed-2018-ICOHabstracts.554}

Introduction Researchers and technicians who work with laboratory animals are exposed to animal allergens and endotoxin in the workplace. Inhalation of these bio-contaminants has been identified as a risk factor for respiratory and allergic diseases resulting in impaired lung function and laboratory animal allergy. The objective of this study was to assess the exposure to environmental endotoxin and rodent allergens to propose the control and preventive measures.

Methods This study was conducted in an animal research facility. Stationary inhalable dust samples were collected using airChek2000 pumps equipped with IOM sampler and glass filter for endotoxin detection (Kinetic LAL assay) and with closed cassette and MCE filter for rat and mouse allergens ELISA analysis. Data were analysed by means of the statistical software R; the influence of changing cages on environmental contamination was assessed by multivariate statistical approaches (mixed effect linear regression models).

Results The concentration of endotoxin during changing cages increases significantly on average by a factor 1.8 with respect to the levels before or after this task $(p=0.0414)$. Moreover, the highest concentration of endotoxin was measured during the preparation of bedding and distribution of feed. The level of Mus m 1 allergen was the most represented (mean=7.4 $\mathrm{ng} / \mathrm{m}^{3}, \sigma=16.5 \mathrm{ng} / \mathrm{m}^{3}$ ). During the changing cages was found a significant increasing of Rat $\mathrm{n} 1$ and Mus $\mathrm{m} \mathrm{1}$; Rat $\mathrm{n} 1$ was also found in mouse rooms showing a contamination probably transported by the operators themselves.

Conclusion The environmental monitoring represents a powerful tool for assessing the determinant factors influencing the increase of endotoxin and animal allergen concentrations as well as underline the role of workers as passive sources of allergens. Furthermore, the identification of exposure peaks may represent an important information for the evaluation of appropriate engineering and preventive control measures particularly for workers employed in specific working tasks.

\section{ASBESTOS IN THE FRENCH NAVY: JOB-EXPOSURE MATRIX}

${ }^{1} \mathrm{~A}$ Maille, ${ }^{2} \mathrm{~N}$ Paleiron, ${ }^{2} \mathrm{~A}$ Pegorie, ${ }^{2} \mathrm{~F}$ Grassin, ${ }^{2} \mathrm{E}$ Rivière, ${ }^{2} \mathrm{M}$ André, ${ }^{3,4} \mathrm{R}$ Pougnet. ${ }^{1}$ Centre médical du 44; ème Régiment de transmission - 67190 Mutzig, France; ${ }^{2}$ Service des maladies respiratoires, HIA Clermont-Tonnerre, Brest, France; ${ }^{3}$ centre des maladies professionnelles et environnementales, CHRU Morvan, Brest, France; ${ }^{4}$ Laboratoire d'études et de recherches en sociologie (LABERS), Université de Bretagne Occidentale, Brest

\subsection{6/oemed-2018-ICOHabstracts.555}

Introduction Asbestos exposure is a concern for the Navy. 94\% of the compensated French soldiers belong to the Navy. While employment-exposure matrices exist for the civilian environment, none are available to the military. Our work aims at creating the first employment-exposure matrix in the French Navy, in order to optimise post-occupational medical surveillance, according to the French health authority.

Method We conducted a bibliographic search for asbestos in naval repair, naval embarking and foreign navies. From databases such as Medline, Pubmed, we used the following Keywords: Navy, Asbestos, Shypyard and Military and we have extended ourselves to the registers of existing theses on the subject.

Results Epidemiological and bibliographic data confirm the increased risk in the French Navy. Three variables are important in the proposal of this employment-exposure matrix: employment, year of arming the ship and duration of embarkation. Risk is important for personnel whose work is in direct contact with asbestos, in particular machine personnel, irrespective of their duration of exposure. For embarked 